\title{
Biomimetic Synthesis, Characterization, and Evaluation of Fluorescence Resonance Energy Transfer, Photoluminescence, and Photocatalytic Activity of Zinc Oxide Nanoparticles
}

\author{
Udari Wijesinghe ${ }^{1}\left(\mathbb{D}\right.$, Gobika Thiripuranathar ${ }^{1, *}\left(\mathbb{D}\right.$, Haroon Iqbal ${ }^{2,+}(\mathbb{D})$ and Farid Menaa ${ }^{3,+}+(\mathbb{D}$ \\ 1 Institute of Chemistry Ceylon, College of Chemical Sciences, Welikada, Rajagiriya 10107, Sri Lanka; \\ udariemalka@ichemc.edu.lk \\ 2 Jiangsu Key Laboratory of Neuropsychiatric Diseases, and College of Pharmaceutical Sciences, \\ Soochow University, Suzhou 215123, China; harooniqbal415@hotmail.com \\ 3 Department of Nanomedicine, California Innovations Corporation, San Diego, CA 92037, USA; \\ dr.fmenaa@gmail.com \\ * Correspondence: tgobika@ichemc.edu.lk \\ + The authors equally contributed to this paper.
}

\section{check for} updates

Citation: Wijesinghe, U.; Thiripuranathar, G.; Iqbal, H.; Menaa, F. Biomimetic Synthesis, Characterization, and Evaluation of Fluorescence Resonance Energy Transfer, Photoluminescence, and Photocatalytic Activity of Zinc Oxide Nanoparticles. Sustainability 2021, 13, 2004. https://doi.org/10.3390/ su13042004

Academic Editor: Zeynep Eren

Received: 25 January 2021

Accepted: 8 February 2021

Published: 12 February 2021

Publisher's Note: MDPI stays neutral with regard to jurisdictional claims in published maps and institutional affiliations.

Copyright: (c) 2021 by the authors. Licensee MDPI, Basel, Switzerland. This article is an open access article distributed under the terms and conditions of the Creative Commons Attribution (CC BY) license (https:/ / creativecommons.org/licenses/by/ $4.0 /)$.

\begin{abstract}
Owing to the development of nanotechnology, biosynthesis of nanoparticles (NPs) is gaining considerable attention as a cost-effective and eco-friendly approach that minimizes the effects of toxic chemicals used in NP fabrication. The present work reports low-cost phytofabrication of zinc oxide ( $\mathrm{ZnO})$ NPs employing aqueous extracts of various parts (leaves, stems, and inflorescences) of Tephrosia purpurea (T. purpurea). The formation, structure, morphology, and other physicochemical properties of ZnO NPs were characterized by ultraviolet-visible (UV-Vis) spectroscopy, X-ray diffraction (XRD), scanning electron microscopy (SEM), transmission electron microscopy (TEM), Fourier transform infrared (FTIR) spectroscopy, and dynamic light scattering (DLS). UV-Vis spectral analysis revealed sharp surface plasmon resonance (SPR) at around 250-280 nm, while the XRD patterns confirmed distinctive peaks indices to the crystalline planes of hexagonal wurtzite $\mathrm{ZnO}$ NPs. TEM analysis confirmed the presence of spherical-shaped ZnO NPs with average particle sizes (PS) between 25-35 nm, which was in agreement with the XRD results. FTIR analysis revealed that phenolics, flavonoids, amides, alkaloids, and amines present in the plant extract are responsible for the stabilization of the ZnO NPs. Further, the hydrodynamic diameter in the range of 85-150 nm was measured using the DLS technique. The fluorescence resonance energy transfer (FRET) ability of biogenic ZnO NPs was evaluated, and the highest efficiency was found in ZnO NPs synthesized via T. purpurea inflorescences extract. Photoluminescence (PL) spectra of biogenic ZnO NPs showed three emission peaks consisting of a UV-Vis region with high-intensity compared to that of chemically synthesized ZnO NPs. The biosynthesized ZnO NPs showed photocatalytic activity under solar irradiation by enhancing the degradation rate of methylene blue (MB). Among the prepared biogenic ZnO NPs, T. purpurea leaves mediated with NPs acted as the most effective photocatalyst, with a maximum degradation efficiency of $98.86 \%$ and a half-life of $84.7 \mathrm{~min}$. This is the first report related to the synthesis of multifunctional $\mathrm{ZnO}$ NPs using T. purpurea, with interesting characteristics for various potential applications in the future.
\end{abstract}

Keywords: phytofabrication; zinc oxide nanoparticles; Tephrosia purpurea; fluorescence resonance energy transfer; photoluminescence; photocatalysis

\section{Introduction}

Nowadays, nanotechnology and nanoscience have gained fascinating meticulous research interest in the areas of physics, chemistry, engineering, and biology. In the domain of nanotechnology, oxide nanoparticles (NPs) have gained importance due to their unique chemical properties, reduced particle size, and high density of corner or 
edge surface sites [1,2]. In recent years, semiconductor metal oxides NPs (MONPs) play a significant role in material science, that is, the fabrication of novel microelectronic circuits, piezoelectric devices, gas sensors, coatings, fuel cells, transparent conductors, biomedical devices, and catalysts [3-7]. Further, MONPs are preferred as sorbents for wastewater treatment containing pigments or dyes over the conventional purification methods, such as flocculation, filtration, precipitation, incineration, bio-treatment, ozonation, chemical coagulation, chemical oxidation, and adsorption processes based on solid adsorbents $[2,5,8]$. MONPs display several advantages owing to their environmental feasibility, extreme photocatalytic activity, simplicity of production, dye degradation process, leading to nontoxic end products without affecting medium parameters such as $\mathrm{pH}$, salt ions content, and temperature [8-10].

Among MONPs, ZnO NPs are versatile n-type semiconductors, which have high electron mobility, a direct wide bandgap of $3.37 \mathrm{eV}$, large exciton binding energy of $60 \mathrm{meV}$ at room temperature (RT), and display high optical transparency and luminescent properties in the near UV-Vis regions [3,9-11]. Due to these properties, ZnO NPs is one of the most promising materials with diverse areas of application in developing piezo-electronics and optoelectronic devices [2,12-16]. Several different physical and chemical methodologies, such as hydrothermal, sonochemical, sol-gel, solvothermal, microemulsion, laser ablation, homogeneous precipitation, thermal decomposition, and microwave irradiation, were developed to synthesize $\mathrm{ZnO}$ NPs with different morphologies [9,17-22]. However, these physio-chemical methods require expensive and toxic chemicals as capping agents, hazardous organic solvents, long reflux time of reaction, and toxic byproducts, subsequently leading to eco-toxicity $[8,23-25]$. Nowadays, biomimetic approaches using various biological resources (e.g., plants, bacteria, algae, actinomycetes, viruses, and fungi) emerge as a promising sector for NP fabrication $[23,25,26]$. Among the various bio-organisms, plants seem to be the best candidates due to their easy availability, low cost, low toxicity, richness in biomolecules, and their simple and reliable capacity for large-scale eco-friendly synthesis of stable, controlled size and shape NPs $[8,24,27]$. Even though an accepted mechanism has not been explored for the biological synthesis of $\mathrm{ZnO} N P s$, the phytochemicals and proteins present in the plant extracts are considered as capping agents and stabilize the formation of NPs via electrostatic and steric interactions [8,26,27].

Herein, we report, for the first time, facile green synthesis of $\mathrm{ZnO} N P s$ via leaves, stems, and inflorescences extracts of T. purpurea. There are about four hundred species of genus Tephrosia distributed throughout the tropical regions of the world [28,29]. Most of the Tephrosia species are highly branched, sub-erect, a herbaceous perennial herb, and are grown like weeds [28]. T. purpurea, also known as Kathurupila, is an important native plant of the Sri Lankan indigenous medicinal system. Traditionally, this plant is mainly used to cure several types of external wounds and gastro-duodenal disorders [28].

It is also used as an anthelmintic and a remedy for asthma, diarrhea, liver disorders, gonorrhea, allergic and inflammatory conditions, hepatitis, rheumatism, ulcers, urinary disorders, bilious febrile attacks, boils, pimples, bleeding piles, fish poison, pain, inflammation, and vomiting-like symptoms [28-31]. Further, it exhibits insect repellant, larvicidal, piscicidal, antimicrobial, anticancer, and antioxidant properties [28,32]. The main phytochemicals of $T$. purpurea were found to be tephrosin, isoflavone, 4,5-dihydroxy3,7-dimethoxyisoflavone, chalcone, tephropurpurin, pongamol, karanjin, lanceolatin B, glycosides (e.g., rutin and quercetin), retenoids (e.g., deguelin, elliptone, and rotenone tephrosin), flavonoids (e.g., purpurin, purpurenone, purpureamethide, and purpuritenin), sterols (e.g., sitosterol), and several fatty acids (e.g., linoleic, oleic, palmitic, stearic, and linolenic acids) $[28,30,33]$. Though T. purpurea is enriched with high medicinal properties, it is not properly utilized, and thus, this study explores the pharmacological and environmental actions of T. purpurea $>$ through $\mathrm{ZnO}$ NPs, providing economic value to the plant with regards to its utility.

Luminescence is one of the fastest-growing, most sensitive, and non-destructive techniques that helps to explain point defects, including extrinsic and intrinsic defects of $\mathrm{ZnO}$ 
NPs $[3,13]$. In addition, ZnO NPs are being applied as bright fluorescent markers with enhanced photostability in fluorescence microscopy, sensor technology, and microarrays, due to their interaction of fluorophores that leads to various spectral changes, such as enhancement of luminescence intensity, photostability, and quantum yield [13,14]. Fluorescence resonance energy transfer (FRET) is a nonradiative quantum mechanical process that relies on the distance and energy transfer from an excited state donor to a ground state acceptor through dipole-dipole interactions $[4,14,34]$; it is widely used in polymer science, biochemistry, and structural biology $[14,34,35]$. The energy transfer between quantum dots has been investigated broadly to design FRET sensors [36,37]. To the best of our knowledge, the present study remains the first attempt to evaluate the efficacy of FRET by ZnO NPs phytosynthesized via T. purpurea. The optical properties of fluorescent molecules located near MONPs are affected by the surface plasmon resonance (SPR) effect $[35,38]$. Adding MONPs to a dye solution may either cause an enhancement or quenching of the fluorescence, depending on the distance between the dye molecules and the MO surface $[4,14,35]$.

Nowadays, dyes and pigments are the most significant pollutants, and even minimal concentration can cause substantial harm in the aquatic ecosystem, changing the physical properties of water, the activity of photosynthetic processes, the aqueous solubility of gases, and sunlight access [8,39]. Among industrial dyes, methylene blue (MB) is one of the most utilized dyes in many manufactured products (e.g., plastics, textile, papers) and toxicology studies, and is an indicator in clinical medicine, and antidote for methemoglobinemia $[9,39,40]$. Nonetheless, MB is a hazardous material that causes many dangerous effects, such as eye irritation, nausea, anemia, and vomiting [9]. Thus, treatment of MB-contaminated water is quite important. Hence, the present study was focused on evaluating the photocatalytic degradation proficiency of $\mathrm{MB}$ in the presence of $\mathrm{ZnO}$ nanocatalysts. During the photocatalytic degradation process, when a photocatalyst is exposed to sunlight, which contains stronger energy than its bandgap energy, the electronhole pair generated on the surface of NPs diffuses out to the surface and partakes in the chemical reaction with the electron acceptor and donor $[2,9,39]$. Thus, $\mathrm{ZnO}$ NPs behave like a smart tool, providing a fast, economical, and eco-friendly solution to treat polluted water, and controlling the removal of organic spices at interfaces $[9,10,40]$.

To the best of our knowledge, this is the first study reporting the biosynthesis and characterizations of $\mathrm{ZnO} N$ Ps using aqueous extracts of the leaves, stems, and inflorescences of T. purpurea. Furthermore, we assessed FRET, photoluminescence (PL), and photocatalytic activities of $\mathrm{ZnO} N P s$ for sustainable environmental remediation.

\section{Materials and Methods}

\subsection{Chemicals and Reagents}

Zinc acetate dihydrate (Anala R grade), and fluorescein were purchased from SigmaAldrich, Mumbai, India. Sodium hydroxide pellet (Anala R grade), hydrochloric acid (Anala $\mathrm{R}$ grade), and methylene blue were purchased from Sisco research laboratories (Pvt) Ltd., New Mumbai, India. Nylosan rhodamin E-BP300 was purchased from Prym Intimates Lanka (Pvt) Ltd., Biyagama, Sri Lanka. Methanol (Anala R grade) was obtained from BDH Industries Ltd., Mumbai, India.

\subsection{Instruments}

The following equipment was used in our study: analytical balance (RADWAG Wagi Electroniczne, AS-220. R2, Poland), $\mathrm{pH}$ meter (Jenway, 3510, UK), advance vortex mixture (VELP Scientifica ZX3, Italy), centrifuge (GEMMYCO, PLC-036H, China), oven (universal oven-UN 55, Germany), UV-Vis spectrophotometer (U-2910- Hitachi, Tokyo, Japan), FTIR spectrometer (Horizon ABB-MB 3000 ATR FT-IR, Canada), spectrofluorometer (F-2700 FL Hitachi, Tokyo, Japan), SEM (Carl Zeiss, Evo, USA), TEM (Hitachi H-600, Tokyo, Japan), particle size analyzer (Malvern NanoZS90, USA), and XRD (Bruker D8 Advance, Tokyo, Japan). 


\subsection{Sample Collection and Preparation of Extracts}

T. purpurea was collected from local agricultural lands of the Anuradhapura district, Sri Lanka. A sample of plant material was taxonomically identified and authenticated by the National Herbarium, Peradeniya, Sri Lanka.

Healthy plants were marked, and leaves (TPL), stems (TPS), and inflorescences (TPF) were collected, washed thoroughly with running water, and subsequently with deionized water $\left(\mathrm{DI} \mathrm{H} \mathrm{H}_{2} \mathrm{O}\right)$. The plant parts were dried at room temperature (RT) in shade for 14 days and then pulverized using a blender; the powder was then stored in an airtight container at RT. The extracts were prepared by placing $5 \mathrm{~g}$ of the finely ground plant material in a flask containing $100 \mathrm{~mL}$ of $\mathrm{DI} \mathrm{H}_{2} \mathrm{O}$, and the solution was heated to $40^{\circ} \mathrm{C}$, with constant stirring for $30 \mathrm{~min}$. The resulting extracts were cooled to RT and filtered using Whatman No.1 filter paper to separate the plant material from the aqueous extract. The collected extract was then stored in a refrigerator for further experiments.

\subsection{Phytogenic Synthesis of $\mathrm{ZnO} N P s$}

The experimental parameters, such as the concentration of $\left[\mathrm{Zn}\left(\mathrm{CH}_{3} \mathrm{COO}\right)_{2}\right] .2 \mathrm{H}_{2} \mathrm{O}$ $(0.01 \mathrm{M}-0.05 \mathrm{M})$, the volume of plant extract $(0.5 \mathrm{~mL}-3 \mathrm{~mL})$, the $\mathrm{pH}(9-13)$, temperature $\left(50{ }^{\circ} \mathrm{C}-100^{\circ} \mathrm{C}\right)$, and reaction time $(0.5-3 \mathrm{~h})$, were optimized for the biogenic synthesis of $\mathrm{ZnO}$ NPs. For the identified optimum conditions, the following synthesis procedure was carried out at RT.

$\left[\mathrm{Zn}\left(\mathrm{CH}_{3} \mathrm{COO}\right)_{2}\right] \cdot 2 \mathrm{H}_{2} \mathrm{O}(0.01 \mathrm{M})$ was first prepared in $50 \mathrm{~mL}$ of $\mathrm{DI} \mathrm{H}_{2} \mathrm{O}$ under constant stirring for $10 \mathrm{~min}$, followed by the addition of $1 \mathrm{~mL}$ of TPL extract. The $\mathrm{pH}$ was then adjusted to 12 by introducing a $2 \mathrm{M}$ sodium hydroxide, which resulted in a pale white solution. The mixture was subjected to vigorous stirring for $2 \mathrm{~h}$ and then centrifuged at $4500 \mathrm{rpm}$ for $15 \mathrm{~min}$. The collected pellets were washed with $\mathrm{DI}_{2} \mathrm{O}$, followed by methanol $(\mathrm{MeOH})$ until the supernatant appeared colorless. The residue was oven-dried at $60^{\circ} \mathrm{C}$ for $12 \mathrm{~h}$, and the obtained $\mathrm{ZnO}$ NPs were preserved in airtight vials for further studies. The synthesis of NPs was repeated by varying the concentrations of $\left[\mathrm{Zn}\left(\mathrm{CH}_{3} \mathrm{COO}\right)_{2}\right] \cdot 2 \mathrm{H}_{2} \mathrm{O}$ for the TPS and TPF extracts. ZnO NPs synthesized via T. purpurea leaves, stems, and inflorescences were denoted as ZnO NPs/TPL, ZnO NPs/TPS, and ZnO NPs/TPF, respectively.

\subsection{Characterization of the Phytogenic $\mathrm{ZnO} N P S$}

UV-Vis spectroscopy was used to observe the optical properties of ZnO NPs in the range of $200 \mathrm{~nm}$ to $800 \mathrm{~nm}$. The phase purity, crystalline size, and shape were characterized by XRD. The morphological features, such as size (particle diameter) and shape of the biosynthesized NPs, were analyzed using SEM and TEM. FTIR was used to identity phytochemical constituents present in the plant extracts and the synthesized ZnO NPs using the technique of Attenuated Total Reflectance in the range of $400-4000 \mathrm{~cm}^{-1}$. Hydrodynamic diameter, size distribution, and polydispersity index (PDI) were measured as a function of time using dynamic light scattering (DLS).

\subsection{FRET Activity of the Phytosynthesized ZnO NPs}

The FRET ability exerted by the ZnO NPs in the presence of fluorescein (Flu) and rhodamine $\mathrm{B}(\mathrm{RhB})$ dyes was evaluated by fluorescence spectrometry. A concentration series of $50 \mu \mathrm{g} \mathrm{mL}^{-1}$ to $600 \mu \mathrm{g} \mathrm{mL}^{-1}$ in $\mathrm{MeOH}$ was prepared for $\mathrm{ZnO}$ NPs synthesized from all three plant parts. A Flu solution $\left(5 \times 10^{-4} \mathrm{~mol} \mathrm{dm}^{-3}\right)$ and a RhB solution $\left(5 \times 10^{-5} \mathrm{~mol} \mathrm{dm}^{-3}\right)$ were prepared in $\mathrm{MeOH}$, and equal volumes ( $400 \mu \mathrm{L}$ each) of Flu and $\mathrm{RhB}$ were mixed with $1000 \mu \mathrm{L}$ of $\mathrm{ZnO}$ NPs, making the final volume $1800 \mu \mathrm{L}$. The treated solutions were mixed by vortexing, and then the fluorescence spectra were recorded, while the emission wavelengths were scanned from $450 \mathrm{~nm}$ to $700 \mathrm{~nm}$ at a fixed excitation of $430 \mathrm{~nm}$.

\subsection{PL of the Phytosynthesized $\mathrm{ZnO} N P s$}

Using a thin-film solid sample, RT-photoluminescence (RT-PL) analysis was carried out for biogenic $\mathrm{ZnO}$ NPs by spectrofluorometer. The light intensity over the cell surface 
was changed by varying the slit length. The PL of the biogenic ZnO NPs was compared to the sample of chemically synthesized ZnO NPs, following the procedure of previously published works $[2,13,41]$, and with appropriate modifications for chemically synthesized $\mathrm{ZnO}$ NPs [42].

\subsection{Photocatalytic Activity of Phytosynthesized ZnO NPS}

The photocatalytic activity of the phytosynthesized ZnO NPs was evaluated by the degradation of $\mathrm{MB}$ under direct sunlight. In a typical process, $20 \mathrm{mg} \mathrm{ZnO}$ NPs were added into a beaker containing $50 \mathrm{~mL}$ of $\mathrm{MB}$ dye solution $\left(5 \mathrm{mg} \mathrm{L}^{-1}\right)$, and the $\mathrm{pH}$ was adjusted to 6. Prior to exposure to sunlight, the suspension was magnetically stirred in the dark for $30 \mathrm{~min}$. A control was kept to monitor the activity in the absence of NPs. Degradation of the $\mathrm{MB}$ was monitored by withdrawing $5 \mathrm{~mL}$ aliquots from the reaction mixture at every 15-min interval. It was then centrifuged to remove all nanocatalysts from the solution, and the absorbance at $662.8 \mathrm{~nm}$ was measured by using a UV-Vis spectrophotometer to assess the rate of percentage degradation. The same experimental procedure was repeated with varying different experimental parameters, such as the catalytic load (10, 15, 20, and $25 \mathrm{mg})$, the concentration of dye $(5,10$, and $15 \mathrm{ppm})$, and $\mathrm{pH}$ of the reaction mixture $(2,4$, 6,8 , and 10).

\section{Results and Discussion}

\subsection{Synthesis and UV-Vis Spectroscopy}

Semiconductor NPs are of great interest due to their ability to demonstrate optical properties in contrast to the bulk materials that arise due to the SPR $[43,44]$. The nature of the plant extract, its concentration, the concentration of the metal salt, the $\mathrm{pH}$, temperature, and reaction time (incubation time) have been identified as crucial factors for the biosynthesis of MONPs $[23,45]$. Optimization of these critical parameters could affect the rate of formation and morphological characteristics of the NPs $[10,23,45]$. The crucial parameters for optimal green synthesis of ZnO NPs have been determined as $0.01 \mathrm{M}, 0.02 \mathrm{M}$, and $0.03 \mathrm{M}\left[\mathrm{Zn}\left(\mathrm{CH}_{3} \mathrm{COO}\right)_{2}\right] \cdot 2 \mathrm{H}_{2} \mathrm{O}$ for the NPs synthesized via TPL, TPF, and TPS, respectively. For all NPs, optimum plant extract volume, $\mathrm{pH}$ of the reaction mixture, drying temperature, and stirring time were commonly identified as $1 \mathrm{~mL}, \mathrm{pH} 12,60{ }^{\circ} \mathrm{C}$, and $2 \mathrm{~h}$, respectively. The $\mathrm{ZnO}$ NPs synthesized at these optimum conditions exhibited a sharp peak in the range of 350-380 nm, which is in agreement with previous studies [8,23,46].

UV-Vis spectroscopy was used as the preliminary identification method for the formation of ZnO NPs and to characterize optical properties [8,10,23,39]. For this process, pale white NPs obtained from each part of the plant (i.e., TPL, TPS, and TPF) were suspended in $\mathrm{DI} \mathrm{H} \mathrm{H}_{2} \mathrm{O}$, and spectrum scans were performed in the range of 200-800 nm. As shown in Figure 1, the optimum $\lambda_{\max }$ values corresponding to the absorption peaks of ZnO NPs/TPL, ZnO NPs/TPS, and ZnO NPs/TPF were observed at $370 \mathrm{~nm}, 367 \mathrm{~nm}$, and $363 \mathrm{~nm}$, respectively. Previous studies showed that the absorption spectra of ZnO NPs generally depend on the parameters, such as size, shape, and temperature $[6,10,23,46]$. With the decrease in average particle size (PS), their resonance absorption peak showed a hypsochromic shift and vice versa [2,6]. In this study, the sharp hypsochromic-shifted absorption peaks obtained confirmed the formation of nanoscale $\mathrm{ZnO}$.

The crystallinity and crystal phase structures of the ZnO NPs synthesized using each part of T. purpurea extracts were characterized by XRD analysis, as shown in Figure 2. XRD patterns of NPs showed the diffraction peaks correspond to Bragg reflections with $2 \theta$ values at $31.75,34.39,36.19,47.57,56.58,62.83,66.28,67.88,69.01,72.47$, and 76.81 and all peaks of the (100), (002), (101), (102), (110), (103), (200), (112), (201), (004), and (202) can be well indexed to hexagonal wurtzite structure. These are in good agreement with the International Center for Diffraction Data (ICDD, Card no. 89-1397), and previous studies on ZnO NPs $[2,9,39,46]$. Moreover, well-defined, high intense, narrow peaks reflected the high crystallinity of ZnO NPs, and the presence of high intense (100), (002), and (101) planes confirmed the pure wurtzite structure [10,40]. The average crystallite 
size (D) was calculated using Debye-Scherrer's formula: $D=K \lambda /(\beta \cos \theta)$, where $D$ represents the crystal size; $\lambda$ denotes the wavelength of the $\mathrm{X}$-ray radiation for $\mathrm{CuK} \alpha ; \mathrm{K}$ is the Scherrer constant, $\theta$ defines the Bragg diffraction angle, and $\beta$ stands for the full-width half-maximum (FWHM).

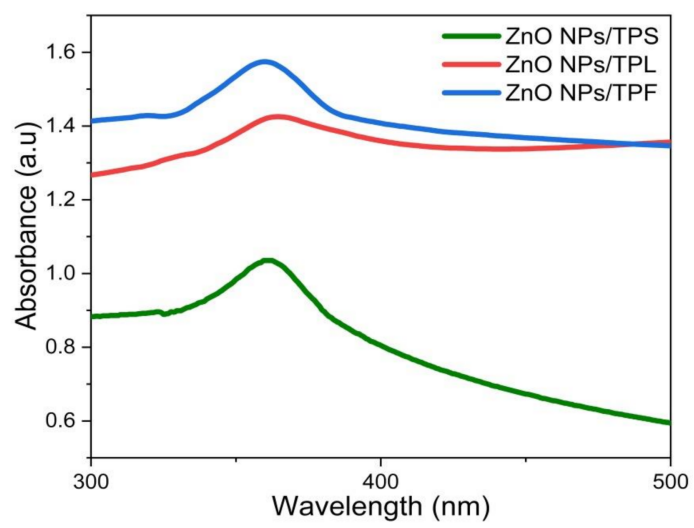

Figure 1. UV-Vis absorbance spectra obtained for the phytosynthesized $\mathrm{ZnO}$ nanoparticles (NPs) at optimized conditions.

\subsection{XRD Analysis}
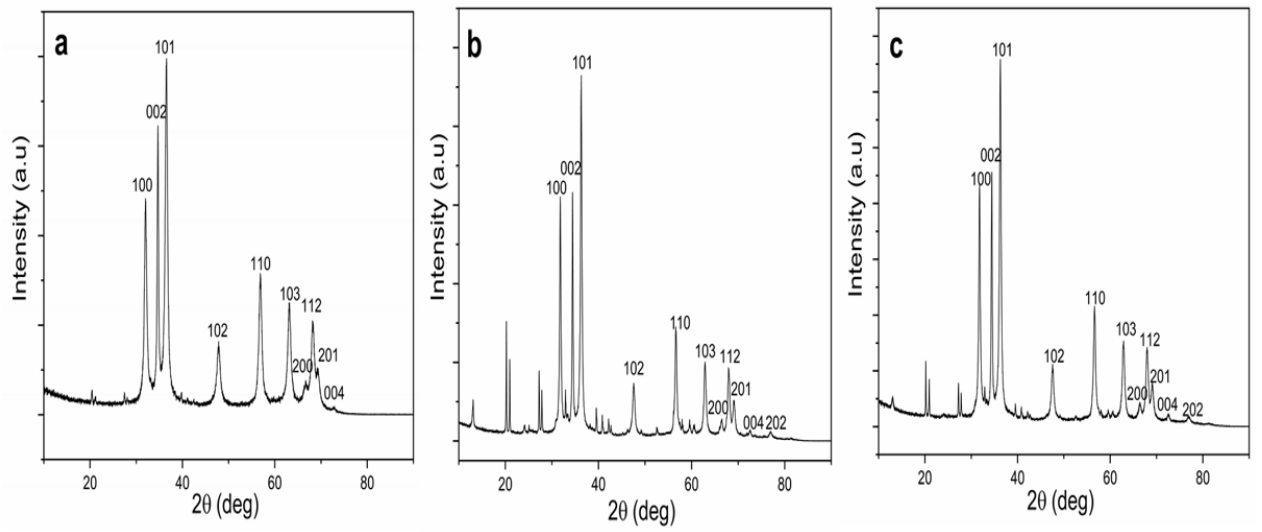

Figure 2. XRD patterns of biosynthesized ZnO NPs. (a) ZnO NPs/TPL; (b) ZnO NPs/stems (TPS); (c) ZnO NPs / inflorescences (TPF).

The average crystallite size of $27.35 \mathrm{~nm}$ was obtained for $\mathrm{ZnO}$ NPs/TPL, corresponding to peak (101) (Table 1). Moreover, the average crystallite size of $25.01 \mathrm{~nm}$ and $34.52 \mathrm{~nm}$ were obtained for ZnO NPs/TPS and ZnO NPs/TPF, respectively (refer to the Supplementary document).

Table 1. Crystal size calculated for ZnO NPs/leaves (TPL) using Debye-Scherrer's formula.

\begin{tabular}{cccc}
\hline $\mathbf{2 \theta}$ & hlk & FWHM & D (nm) \\
\hline 31.75 & $(100)$ & 0.58 & 14.82 \\
34.39 & $(002)$ & 0.32 & 14.49 \\
36.19 & $(101)$ & 0.60 & 27.35 \\
47.57 & $(102)$ & 0.88 & 10.33 \\
56.58 & $(110)$ & 0.70 & 13.44 \\
62.83 & $(103)$ & 0.80 & 12.12 \\
67.88 & $(112)$ & 0.69 & 14.05 \\
69.01 & $(201)$ & 1.43 & 7.01 \\
\hline
\end{tabular}




\subsection{Surface Morphological Analysis}

The identification of physicochemical properties of the NPs, such as size, shape, surface roughness, agglomeration, and aggregation state, is important, as they play a vital role in optoelectrical, biomedical, environmental applications, as well as for the purpose of minimizing toxicity and biological fate [20,47]. The analysis was carried out in different magnitudes $(15,000,25,000$, and 50,000) at 10,000 kV, and the obtained SEM micrographs of phytosynthesized ZnO NPs at 25,000 are shown in Figure 3 (SD in Figures 1-3 for 15,000 and 50,000). Topographical images displayed flower-like ZnO NPs/TPL composed of clusters of individual nanocrystals with a roughly spherical shape (Figure 3a), while the quasi-spherical shape was prominent for ZnO NPs/TPS (Figure 3b) and ZnO NPs/TPF (Figure 3c). ZnO NPs/TPL shows different surface morphology compared to that of $\mathrm{ZnO}$ NPs synthesized from TPS and TPF, and this may be due to the amount and types of biomolecules present in the plant extracts. SEM depicted both individual and some aggregate NPs with a consistent average size of $85-89 \mathrm{~nm}$, precisely $87.5 \pm 14.45 \mathrm{~nm}$ in $\mathrm{ZnO}$ NPs/TPL, $85.43 \pm 7.11 \mathrm{~nm}$ in ZnO NPs/TPS, and $88.14 \pm 9.15 \mathrm{~nm}$ in ZnO NPs/TPF.

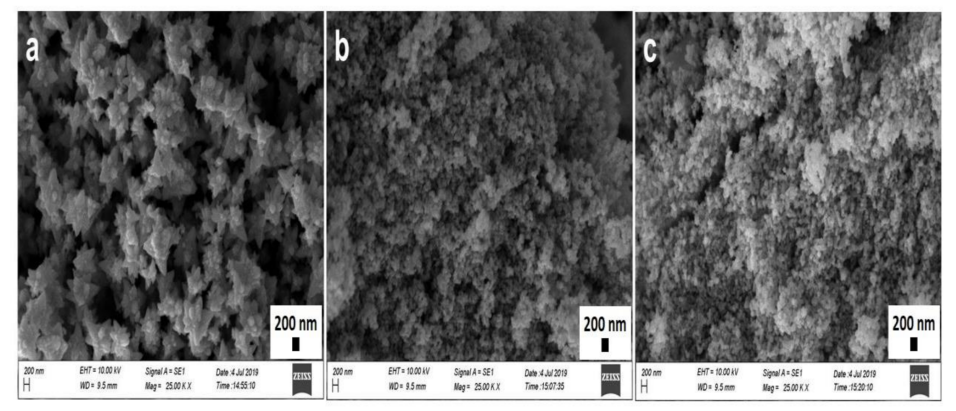

Figure 3. SEM micrographs of ZnO NPs (magnification: $25 \times$, scale bar: $200 \mathrm{~nm}$ ). (a) ZnO NPs/TPL; (b) ZnO NPs/TPS; (c) ZnO NPs /TPF.

SEM images of biomimetically synthesized ZnO NPs obtained from T. purpurea extract proved that the NPs are smaller than those reported previously [48].

As a complementary technique, TEM analysis was performed to identify the morphology, nature, and size of the phytosynthesized ZnO NPs. TEM micrographs revealed that all the phytosynthesized NPs were spherical-shaped, falling within the nano range (Figure 4). The previous studies suggest that the high annealing temperatures $\left(100-500^{\circ} \mathrm{C}\right)$ exert an effect on crystal growth, loss of bioactive compounds (stabilizers), and transform the shape of the NPs $[6,8,46]$. Wherein a moderate temperature of $60^{\circ} \mathrm{C}$ was selected as the drying temperature, protected surface-adhered phytochemicals resulted in the formation of well-distributed NPs without aggregation (Figure 4) [49]. The average particle diameter of $\mathrm{ZnO}$ NPs varied from $26 \mathrm{~nm}$ to $35 \mathrm{~nm}$ and was found to be $27.23 \pm 14.04 \mathrm{~nm}$ (ZnO NPs/TPL), $26.64 \pm 6.22 \mathrm{~nm}$ (ZnO NPs/TPS), and $34.58 \pm 10.8 \mathrm{~nm}$ (ZnO NPs/TPF). The crystallinity and the PS determined for all the samples by TEM are in good agreement with the $X R D$ results.

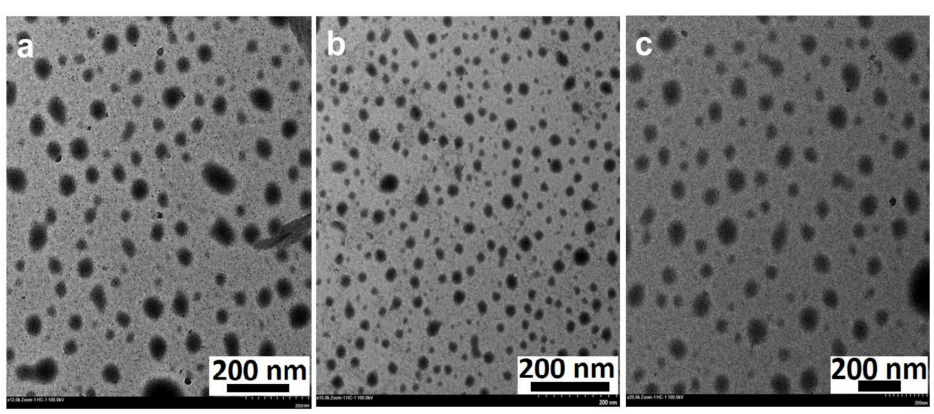

Figure 4. TEM images of ZnO NPs (magnification: 20×, scale bar: $200 \mathrm{~nm}$ ). (a) ZnO NPs/TPL; (b) ZnO NPs/TPS; (c) ZnO NPs/TPF. 


\subsection{FTIR Spectroscopic Analysis}

To identify the surface-adhered functional groups present in the NPs, FTIR spectroscopy was performed and the resulting spectra are depicted in Figure 5. Substancespecific IR vibrations of the molecules led to specific signals in the range of $400-4000 \mathrm{~cm}^{-1}$. The low-intensity IR peaks observed in the ZnO NPs may be due to the removal of surfaceadhered phytochemicals in the washing step with $\mathrm{MeOH}$. Consistently, prominent peaks in all spectra from plant extracts were observed in the wavelength ranges of $3200-3350 \mathrm{~cm}^{-1}$, $1550-1650 \mathrm{~cm}^{-1}$, and 500-600 $\mathrm{cm}^{-1}$, which are attributed to $-\mathrm{OH}, \mathrm{C}=\mathrm{O}$ or $\mathrm{C}=\mathrm{C}$, and C-Br stretching, respectively. The peak at $2100-2260 \mathrm{~cm}^{-1}$ appeared only in the TPS extract, which corresponds to $C \equiv C$ vibration. All the phytosynthesized NPs exhibit prominent peaks in the ranges of $3200-3300 \mathrm{~cm}^{-1}, 2850-3000 \mathrm{~cm}^{-1}, 2100-2260 \mathrm{~cm}^{-1}$, and $800-1000 \mathrm{~cm}^{-1}$, indicating the presence of $-\mathrm{OH}$ stretch, $\mathrm{CH}$ alkene stretch, $\mathrm{C} \equiv \mathrm{C}$ stretch, and $=\mathrm{CH}$ bending, respectively. As per the published literature, the $\mathrm{Zn}-\mathrm{O}$ peak that appears within the range of $500-600 \mathrm{~cm}^{-1}$ indicates the presence of hexagonal wurtzite $\mathrm{ZnO}$ NPs $[20,46,50,51]$, confirming our previous observations by XRD analysis.
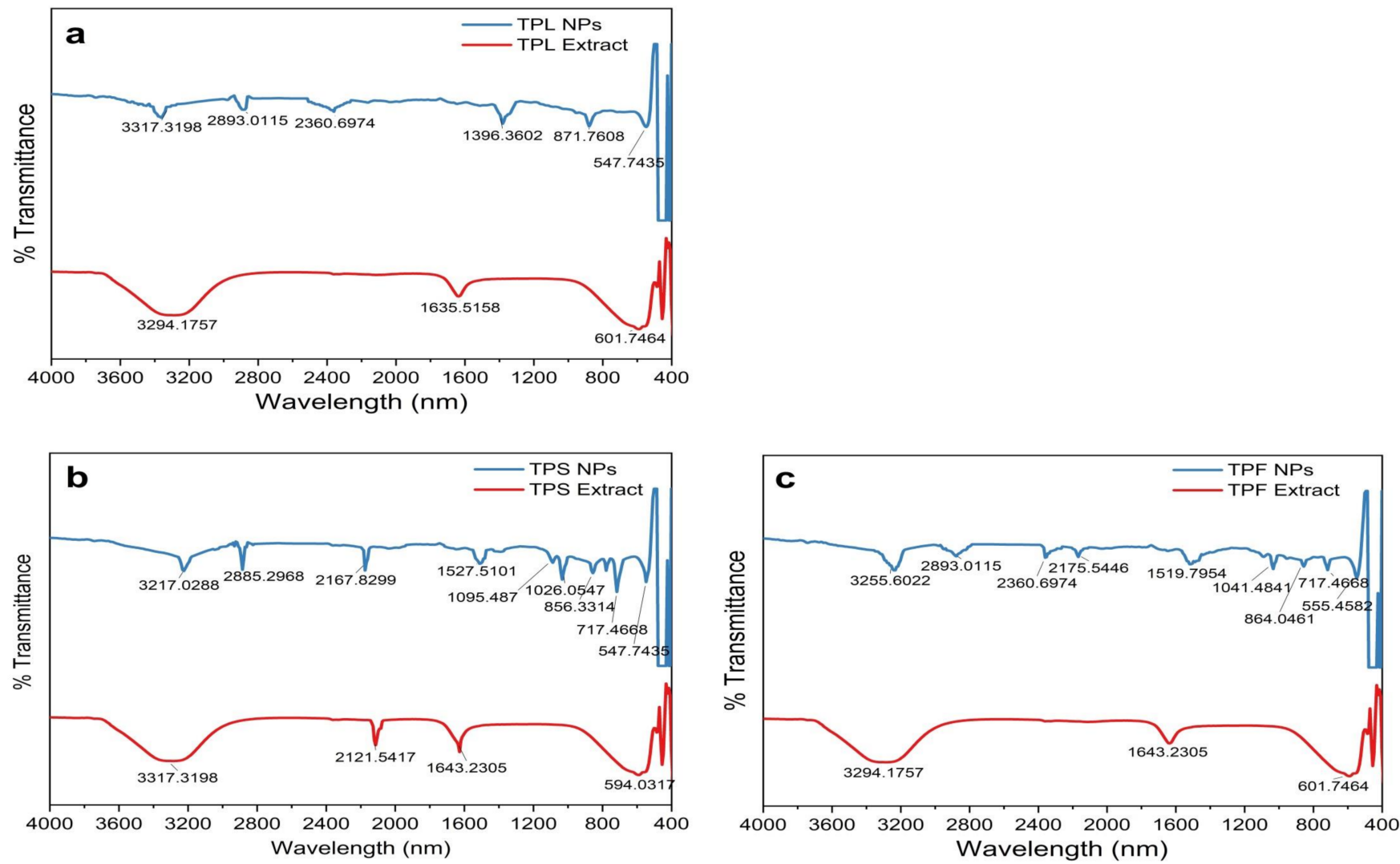

Figure 5. FTIR spectrogram of plant parts and synthesized ZnO NPs. (a) ZnO NPs/TPL; (b) ZnO NPs/TPS; (c) ZnO NPs/TPF.

$\mathrm{ZnONPs} / \mathrm{TPS}$ and ZnO NPs/TPF showed miniature peaks in the ranges of 1500-1650 $\mathrm{cm}^{-1}$, $1000-1200 \mathrm{~cm}^{-1}, 1000-1100 \mathrm{~cm}^{-1}$, and $650-750 \mathrm{~cm}^{-1}$, corresponding to the symmetric stretching of the carbonyl side groups in the amino acid residues of the protein molecules, the $\mathrm{CN}$ stretch of aliphatic amines, alkanes, and supposedly, the $\mathrm{CH}$ bend in alkynes, respectively. The peak at $1350-1400 \mathrm{~cm}^{-1}$ is assigned to $\mathrm{CH}$ bending in the $-\mathrm{CH}_{2}$ group found only in ZnO NPs/TPF. The IR bands rationalize that the aqueous extract of T. purpurea is rich in phenolic compounds, saponins, flavonoids, amide, tannins, alkaloids, and amines. Thus, the involvement of these secondary metabolites as capping agents induced NP stabilization, thus aiding the formation of $\mathrm{ZnO}$ NPs $[8,23,48,49]$. 


\subsection{DLS Analysis}

The variation in PS could be attributed to the polydisperse nature of NPs. The PDI represents the degree of "non-uniformity" of the distribution and is related to the existence of NPs as aggregates or agglomerates, causing variability in the calculated PS in comparison with the theoretical size [23]. DLS is an emerging non-invasive technique that is extensively used to determine the PS and the PS distribution of NPs. The PS was calculated by the hydrodynamic diameter based on Brownian movements exhibited by the particles. The average hydrodynamic diameter was in the range of $85-150 \mathrm{~nm}$, which is quite larger than the theoretical size reported by XRD and TEM (Figure 6). The average PS was found to be $140.19 \mathrm{~nm}(\mathrm{PDI}=0.213)$ in $\mathrm{ZnO} N P s / \mathrm{TPL}, 147.63 \mathrm{~nm}(\mathrm{PDI}=0.192)$ in $\mathrm{ZnO} N P s / \mathrm{TPS}$, and $141.62 \mathrm{~nm}(\mathrm{PDI}=0.2)$ in $\mathrm{ZnO} \mathrm{NPs} / \mathrm{TPF}$.
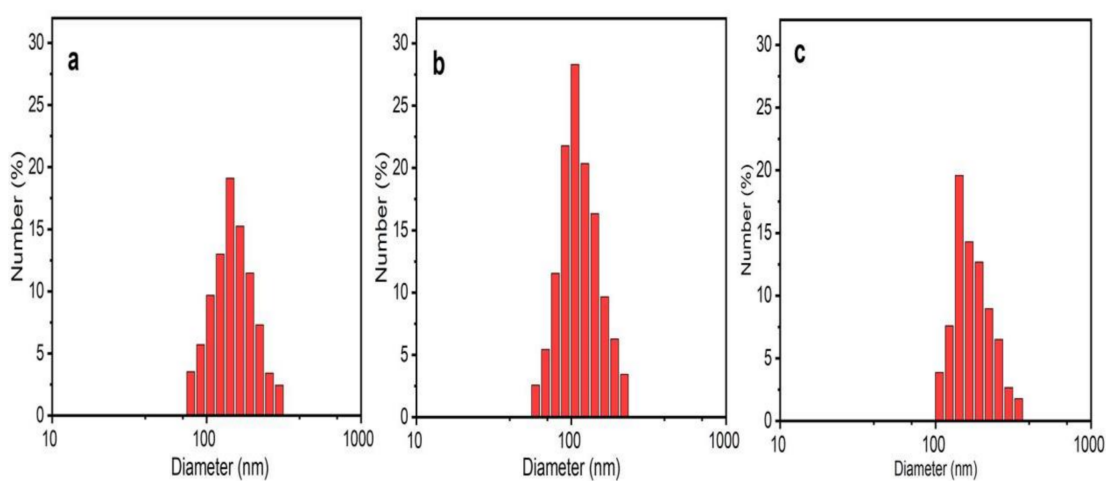

Figure 6. ZnO NPs size distribution by DLS. (a) ZnO NPs/TPL; (b) ZnO NPs/TPS; (c) ZnO NPs/TPF.

\subsection{FRET Ability of Phytosynthesized $\mathrm{ZnO}$ NPs}

The FRET is a non-radiative quantum mechanical process that strongly depends on distance (1-10 $\mathrm{nm}$ between donor-acceptor), where energy transfer occurs from an excited state donor to a ground state acceptor through dipole-dipole interactions $[4,14,37]$. This process has wide applications in structural biology, detection and visualization of intermolecular association, biomolecular conformations and dynamics, development of intermolecular binding assays, polymer science, and laser dyes $[4,14,34,35]$. It has been identified that NPs are capable of manipulating the FRET process (donor-acceptor interaction) by increasing the local electrical field surrounding them and manipulating the radiative and non-radiative decay of fluorescent dyes [4]. Hence, the interest in studying FRET in the presence of NPs has increased, and several studies have reported the usage of $\mathrm{ZnO}$ NPs as an energy donor or to control the energy transfer process [14]. It has been shown that the spectral overlap integral, the orientation of transition dipole moment of the donor and acceptor, fluorescence lifetime, size and shape of the NPs, radiative decay rate, and quantum yield of the donor molecule affect the strength of FRET [35,52].

Fluorescence enhancement near the NPs' surfaces occurred due to interaction with SPR, a decrease in non-radiative decay, an increase in photostability of the dye, and the change in local dielectric properties of the medium $[14,35,52]$. Thus, to observe a sufficient fluorescence enhancement, the dye molecules should be located at a greater distance $(>10 \mathrm{~nm})$ from the metal surface [52]. Moreover, the size and morphology alter the energy band gap of the NPs, which in turn affect the spectral characteristics and FRET efficiency [4]. However, the exact mechanism for the enhanced fluorescence intensity of the dyes in the presence of $\mathrm{ZnO}$ NPs is yet to be explored.

The present study investigated the FRET between two organic dyes, Flu (donor) and $\mathrm{RhB}$ (acceptor), which were prepared in a $\mathrm{MeOH}$ solution in the presence and absence of the greenly synthesized ZnO NPs. In FRET studies, Flu and RhB dyes are extensively used, due to their excellent luminescence properties, such as a high absorption coefficient, high photostability, high fluorescence quantum yield, and relatively long emission wavelength $[14,38]$. Flu and RhB show maximum absorbance at around $475 \mathrm{~nm}$ and $525 \mathrm{~nm}$, with the prominent 
monomer fluorescence bands around $510 \mathrm{~nm}$ and $552 \mathrm{~nm}$, respectively [14,38,53,54]. The analysis was carried out at a fixed excitation wavelength of $430 \mathrm{~nm}$, which was chosen to direct excited Flu, avoiding the emission and absorption spectral overlap of Flu and RhB. Further, at this wavelength, ZnO NPs show negligible fluorescence, which does not affect FRET parameters between Flu and RhB. To obtain a solid understanding of FRET, fluorescence emission was recorded for Flu, $\mathrm{RhB}$, and the Flu-RhB mixture in the presence of ZnO NPs (i.e., ZnO NPs/TPL, ZnO NPs/TPS, and ZnO NPs/TPF), and compared with their controls (pure dyes without NPs). Interestingly, it has been noted that the significant fluorescence enhancement of Flu occurred in the presence of ZnO NPs (Figure 7a), whereas $\mathrm{RhB}$ fluorescence enhancement was almost insignificant (Figure $7 \mathrm{~b}$ ).
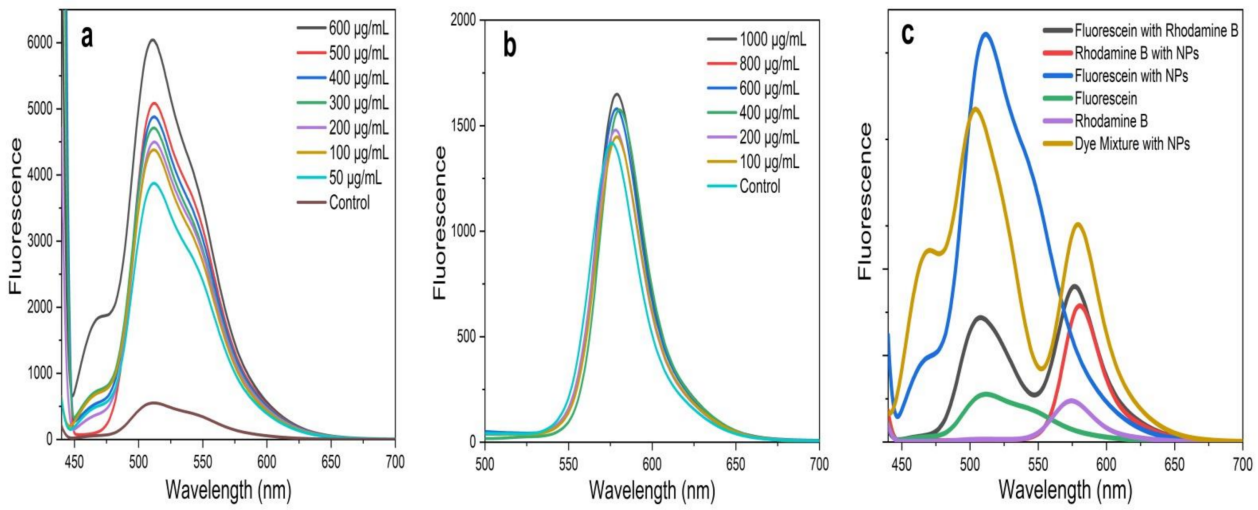

Figure 7. (a) Fluorescence spectrum of fluorescein (Flu) with ZnO NPs/TPS; (b) fluorescence spectrum of rhodamine B (RhB) with ZnO NPs/TPS; (c) variation of fluorescence emission intensity of Flu and/or RhB in the presence and absence of ZnO NPs/TPS $(500 \mu \mathrm{g} / \mathrm{mL})$ at an excitation wavelength of $430 \mathrm{~nm}$.

According to the literature, fluorescence enhancement of Flu is due to the interaction caused by $\mathrm{Zn}^{2+}$ ions in the $\mathrm{ZnO}$ matrix with a carbonyl group present in Flu $[14,55]$. These interactions reduce the energy of the conduction band and increase the energy of the valence band of Flu, thus increasing the excitation rate of the fluorophores, leading to fluorescence enhancement [55]. A similar effect cannot be observed with RhB due to the absence of carbonyl groups, and, at $430 \mathrm{~nm}$ excitation, RhB showing negligible absorption [14]. However, when compared to their pure counterparts, the fluorescence spectrum of the Flu-RhB mixed solution (Figure 7c) showed that the fluorescence intensity of Flu decreased when RhB increased. Also, a sufficient fluorescence spectral overlap of Flu and/or RhB with and without TPS-mediated NPs at $500 \mu \mathrm{g} / \mathrm{mL}$ concentration is depicted in Figure 7c. This increase in RhB fluorescence was due to the light absorption by Flu molecules, which did transfer the energy to RhB via FRET. It has been observed that biogenic ZnO NPs act as energy donors and manipulate energy transfer processes by enhancing FRET efficiency. Interestingly, with the increase in the concentration of $\mathrm{ZnO}$ NPs, the FRET efficiency increased between Flu and RhB.

The FRET efficiency was calculated by using the following formula: $E=1-\left(\mathrm{F}_{\mathrm{AD}} / \mathrm{F}_{\mathrm{D}}\right)$ $\times 100 \%$ (at $600 \mu \mathrm{g} / \mathrm{mL}$ of NPs) $[14,34,56]$, where $F_{D A}$ is the relative fluorescence intensity of the donor in the presence of the acceptor and $F_{D}$ is the fluorescence intensity of the donor in the absence of the acceptor. A FRET efficiency of $77.45 \%$ was found for $\mathrm{ZnO}$ NPs /TPF, while 41.32\% and 26.33\% were observed for ZnO NPs/TPS, and ZnO NPs/TPL, respectively (Figure 8). 

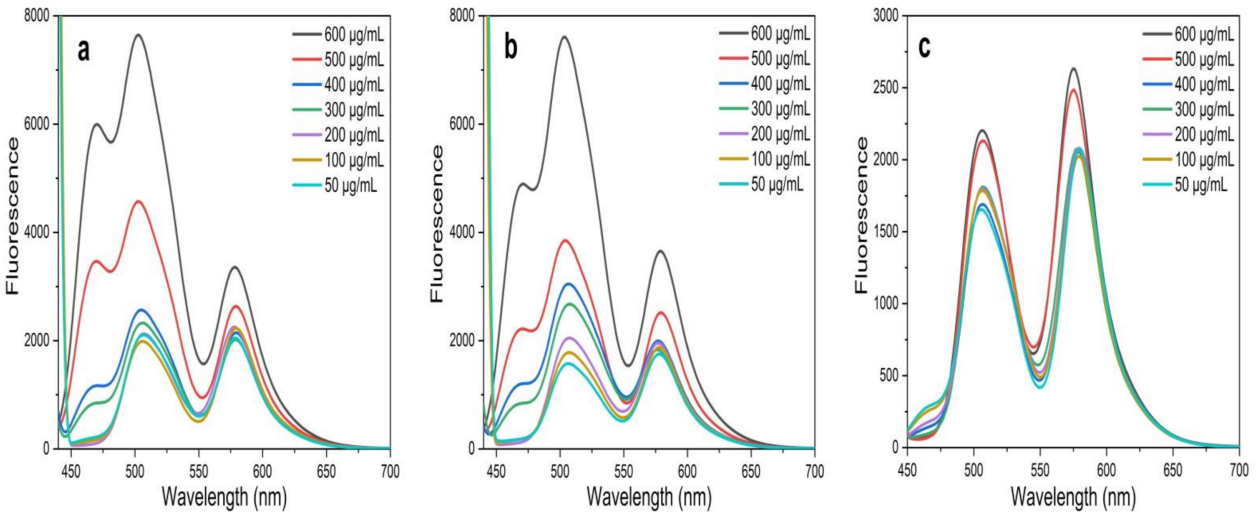

Figure 8. FRET spectra in the presence of Flu-RhB at an excitation wavelength of $430 \mathrm{~nm}$. (a) $\mathrm{ZnO}$ NPs/TPL; (b) ZnO NPs/TPS; (c) ZnO NPs/TPF.

\subsection{PL Activity of Synthesized ZnO NPs}

The optoelectronic properties of semiconductor NPs like ZnO NPs have gained tremendous interest in recent years, and the photoconductivity of these NPs arises due to the photogeneration of electron-hole pairs after the absorption of photons [13]. Besides, $\mathrm{ZnO}$ NP properties are strongly affected by extrinsic and intrinsic defects and impurities $[3,13]$. PL spectroscopy was used to identify the efficiency of the charge carrier separation and point defects in $\mathrm{ZnO}$ NPs, such as oxygen vacancies $\left(\mathrm{V}_{\mathrm{o}}\right)$, oxygen interstitials $\left(\mathrm{O}_{\mathrm{i}}\right)$, zinc vacancies $\left(\mathrm{V}_{\mathrm{Zn}}\right)$, zinc interstitials $\left(\mathrm{Zn}_{\mathrm{i}}\right)$, and oxygen antisites in $\mathrm{ZnO} N P s[3,13]$.

Figure 9 illustrates the RT-PL emission spectrum of ZnO NPs/TPL, ZnO NPs/TPS, and $\mathrm{ZnO}$ NPs/TPF in comparison with chemically synthesized ZnO NPs, at the excitation wavelength of $295 \mathrm{~nm}$. Previous studies revealed that PL emission depends on the excitation wavelength $[11,57]$. Interestingly, our data revealed that the maximum PL intensity can be achieved only when the excitation wavelength is at $295 \mathrm{~nm}$ and a wavelength above or below this value causes changes in the position of the peaks. Indeed, at this excitation, all the $\mathrm{ZnO}$ samples exhibited band edge emission at $392 \mathrm{~nm}$ in the $\mathrm{UV}$ region and deep trap state emission related to blue emission at $453 \mathrm{~nm}$ and yellow emission at $597 \mathrm{~nm}$ in the visible region (Figure 10). Generally, the less intense and broad peaks found at $392 \mathrm{~nm}$ are attributed to the free recombination of excitons that originated from the localized level slightly below the conduction band to the valence band, due to the electron transition $[3,12,58]$. Besides, peaks that appeared at around $453 \mathrm{~nm}$ were related to intrinsic surface defects of $\mathrm{ZnO}$ nanostructures originating from the zinc interstitials and/or oxygen vacancies and may have been due to singly ionized chargers located at $\sim 0.21 \mathrm{eV}$ above the valence band $[3,20,58]$. Studies reported that the apparition of electron capture on the surfaces of NPs causes quenching of blue emission [12]. However, the detailed mechanism for blue emission at $453 \mathrm{~nm}$ has not yet been explored.
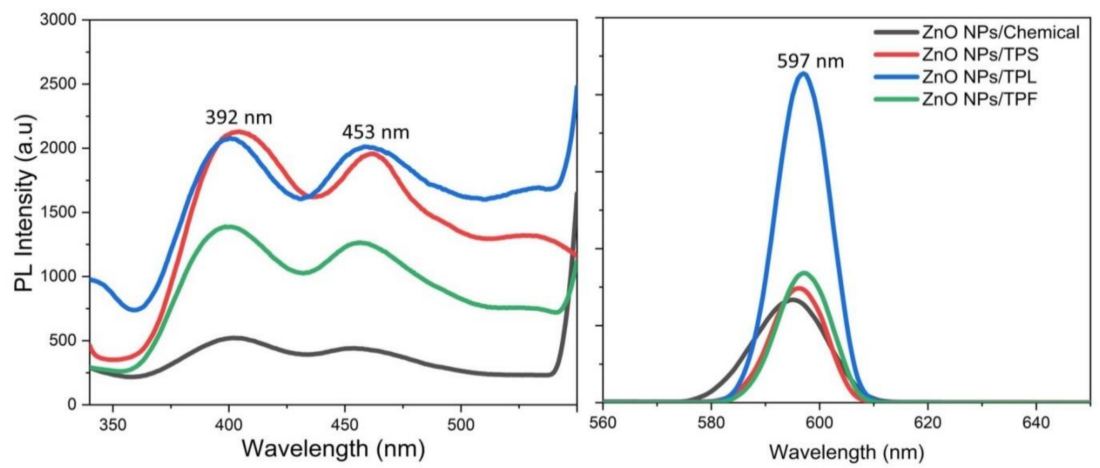

Figure 9. Photoluminescence (PL) spectrums of ZnO NPs recorded with the excitation wavelength of $295 \mathrm{~nm}$ 


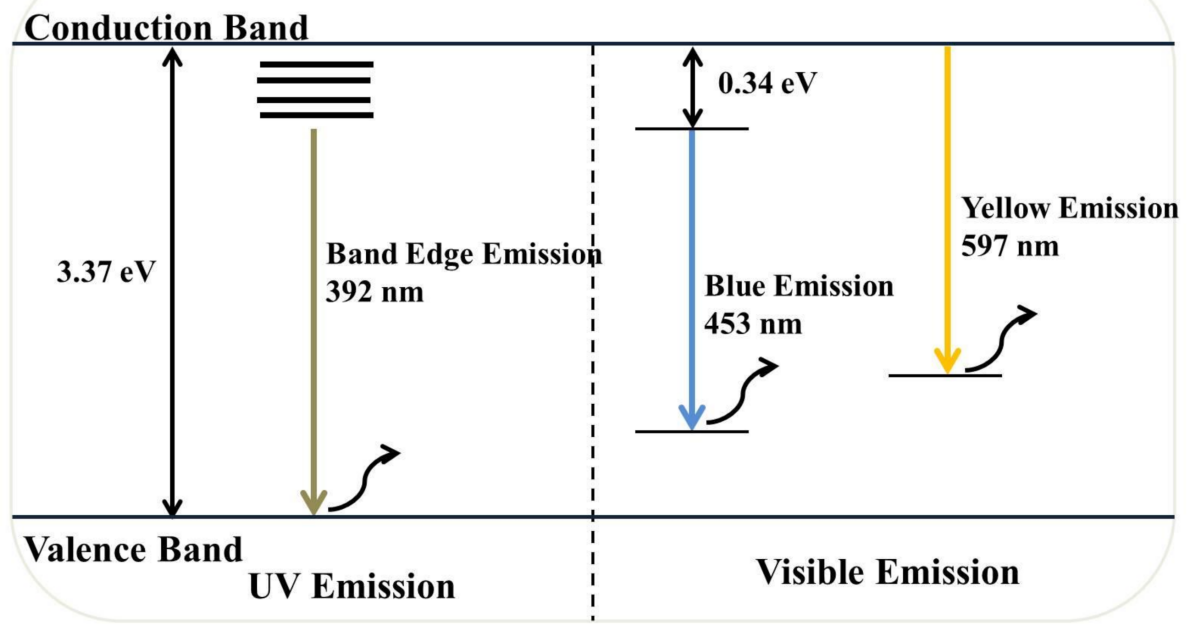

Figure 10. Schematic illustration of the phytogenic ZnO NP-mediated PL mechanism.

Eventually, the third major emission edge was observed at $592 \mathrm{~nm}$, attributing to pure yellow emission. Thus, the sharp emission resulted from the recombination of photogenerated holes in oxygen interstitial with singly ionized charge/delocalized electrons of intrinsic defects of oxygen vacancies and zinc interstitials $[2,20]$. The green emission reported by many authors at $524 \mathrm{~nm}$ was not observed in this study $[3,58,59]$. The absence of green emission implies that synthesized NPs are highly pure and free of contaminants, confirming the obtained XRD results. Moreover, the reduction of $\mathrm{Zn}^{2+}$ ions did not occur in the synthesis process, and green synthesis carried out in the absence of a reducing atmosphere inhibits the presence of oxygen vacancies, thereby quenching the green emission. Taken together, the obtained results revealed higher PL intensity for all biogenic ZnO NPs, compared to that of the chemically synthesized.

\subsection{Photocatalytic Activity of Phytosynthesized $\mathrm{ZnO}$ NPs}

Recently, various studies reported the catalytic effect of bio-fabricated ZnO NPs in the degradation of organic pollutants $[8,39,40]$. Interestingly, nanosized $\mathrm{ZnO}$ acts as an effective photocatalyst for the degradation of dye contaminants in water under UV light and/or sunlight $[2,5,60]$. The particle size, shape, phase composition, surface area, surface hydroxyl group density, and bandgap of the photocatalyst are considered as major factors that affect the efficiency of photodegradation $[5,8]$. Hence, the present study was carried out by utilizing phytofabricated $\mathrm{ZnO}$ NPs/TPL, ZnO NPs/TPS, and ZnO NPs/TPF for the degradation of $\mathrm{MB}$ under solar irradiation.

The simplest mechanism of MB photodegradation in the presence of phytosynthesized $\mathrm{ZnO}$ NPs has been clarified in this study (Figure 11). Thereby, under irradiation, photoinduced molecular reactions take place at the surface of the nanocatalyst. ZnO NPs absorbed photon energy equal to or higher than the bandgap energy to create holes $\left(\mathrm{h}^{+}\right)$in the valence band and the electrons $\left(\mathrm{e}^{-}\right)$in the conduction band. The free holes oxidized neighboring $\mathrm{H}_{2} \mathrm{O}$ molecules into hydroxyl radicals $\left({ }^{\bullet} \mathrm{OH}\right)$, while the electron in the conduction band lessened the $\mathrm{O}_{2}$ adsorption by converting $\mathrm{O}_{2}$ into superoxide radicals $\left(\mathrm{O}_{2}{ }^{\bullet-}\right)$. These species act as strong oxidizing agents that are highly reactive and oxidize $\mathrm{MB}$ to $\mathrm{CO}_{2}, \mathrm{H}_{2} \mathrm{O}$, and inorganic acids $[5,9,40]$. 


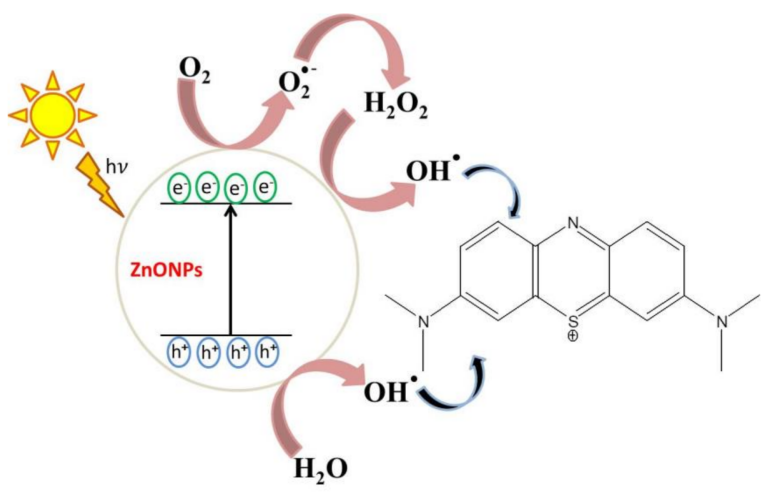

Figure 11. Proposed photocatalytic reaction mechanism of phytosynthesized ZnO NPs.

Photocatalytic activity of ZnO NPs mainly depends on the amount of the catalyst, the initial concentration of MB dye, and the $\mathrm{pH}$ of the reaction mixture $[39,40,61]$. The results obtained for $\mathrm{ZnO}$ NPs/TPL (Figure 12a-c) are elaborately discussed here and reflect what was noticed also with ZnO NPs/TPS and ZnO NPs/TPF when tested in the same experimental conditions.
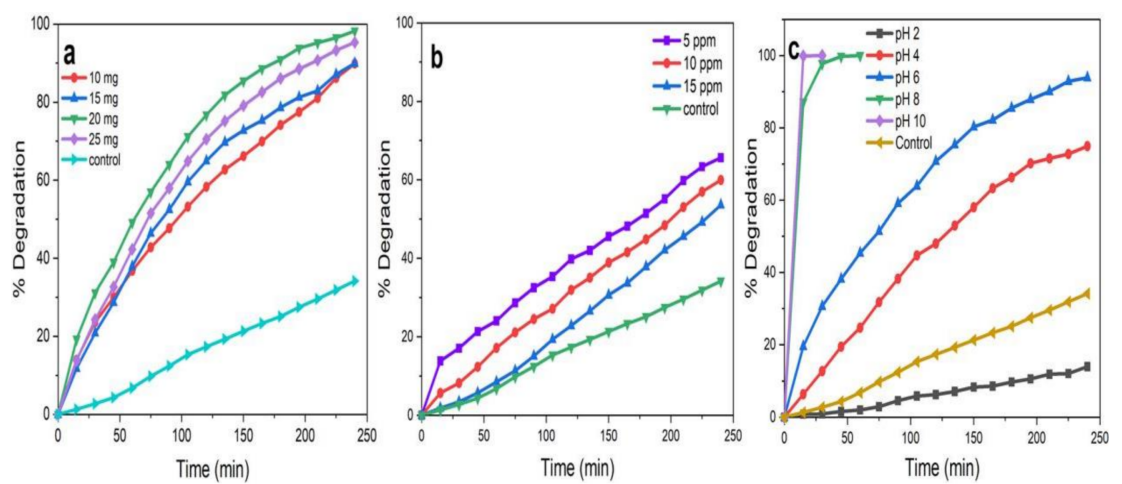

Figure 12. ZnO NPs/TPL-mediated photocatalytic degradation in various physio-chemical conditions. (a) Catalytic load concentration; (b) methylene blue (MB) concentrations at a fixed catalytic load of $20 \mathrm{mg}$; (c) pH at a fixed catalytic load of $20 \mathrm{mg}$ and $5 \mathrm{ppm}$ dye concentration.

Figure 12a displays the degradation of MB dye by keeping the concentration of $\mathrm{MB}$ constant $(5 \mathrm{ppm})$ and varying the catalytic load $(10,15,20$, and $25 \mathrm{mg})$ at $\mathrm{pH} 6$. It was revealed that with the increase in catalytic load from 10 to $20 \mathrm{mg}$, the rate of dye degradation increased by $9 \%$. This is because the availability of active sites of the photocatalyst increased on the surface, making them easily participate in photoactivity $[2,9,40]$. However, the further increment of photocatalyst concentration (>20 mg), caused the aggregation of NPs, resulting in a decrease in the number of surface active sites and specific surface area. Further, this affected the penetration of light through the medium, leading to poor opacity and scattering of light, resulting in poor degradation $[9,10]$. Therefore, the catalytic load of $20 \mathrm{mg}$ of the reaction mixture was considered for further studies.

To investigate the maximum concentration of dye for efficient degradation, the reaction mixture was tested at varying concentrations of dye $(5,10,15 \mathrm{ppm})$, keeping a constant catalytic load (20 mg) and pH (6) in the presence of sunlight (Figure 12b). The data analysis proved that when the dye concentration increased from 5 to $15 \mathrm{ppm}$, the photocatalytic degradation was reduced by $12 \%$. Thus, 5 ppm of MB having a catalytic load of $20 \mathrm{mg}$ would be the optimum concentration for further studies. Generally, as the concentration of dye increased, the rate of degradation was decreased by reducing active site densities $\left({ }^{\bullet} \mathrm{OH}\right)$ on the surface of the NPs $[5,9,10]$.

The effect of $\mathrm{pH}$ on the degradation of dye was assessed by varying $\mathrm{pH}$ in the range of $2-10$ by maintaining a constant the catalyst load $(20 \mathrm{mg})$ and concentration of dye (5 ppm), 
as represented in Figure 12c. The results revealed that the degradation of MB was excellent in alkaline $\mathrm{pH}$, with the highest rate of degradation observed at $\mathrm{pH} 10$. This degradation may also be attributed to the instability of the dye in alkaline $\mathrm{pH}$ and can be explained based on zero potential charges [62]. Conversely, ZnO NPs tended to dissolve at acidic $\mathrm{pH}(\mathrm{pH} 2$ and $\mathrm{pH} 4)$, resulting in quite a low degradation efficiency. Therefore, $\mathrm{pH} 6$ was selected, which facilitated monitoring the degradation of $\mathrm{MB}$ without self-degrading the $\mathrm{MB}$ or dissolving the $\mathrm{ZnO}$ NPs.

By using the above-mentioned optimized conditions ( $20 \mathrm{mg}$ catalyst, $5 \mathrm{ppm} \mathrm{MB}$, and $\mathrm{pH}$ 6), the photocatalytic degradation of $\mathrm{MB}$ was tested for $240 \mathrm{~min}$ under direct sunlight for the mixture without $\mathrm{ZnO}$ NPs (control) (Figure 13a), ZnO NPs/TPL (Figure 13b), ZnO NPs/TPS (Figure 13c), ZnO NPs/TPF (Figure 13d). UV-Vis absorbance spectra of the MB treated with any of the biogenic ZnO NPs under sunlight, demonstrated a significant and time-dependent degradation of the MB compared to the control. Moreover, it could be observed that the absorption intensity decreased with time considerably, within the first $30 \mathrm{~min}$ in samples, compared to the control.
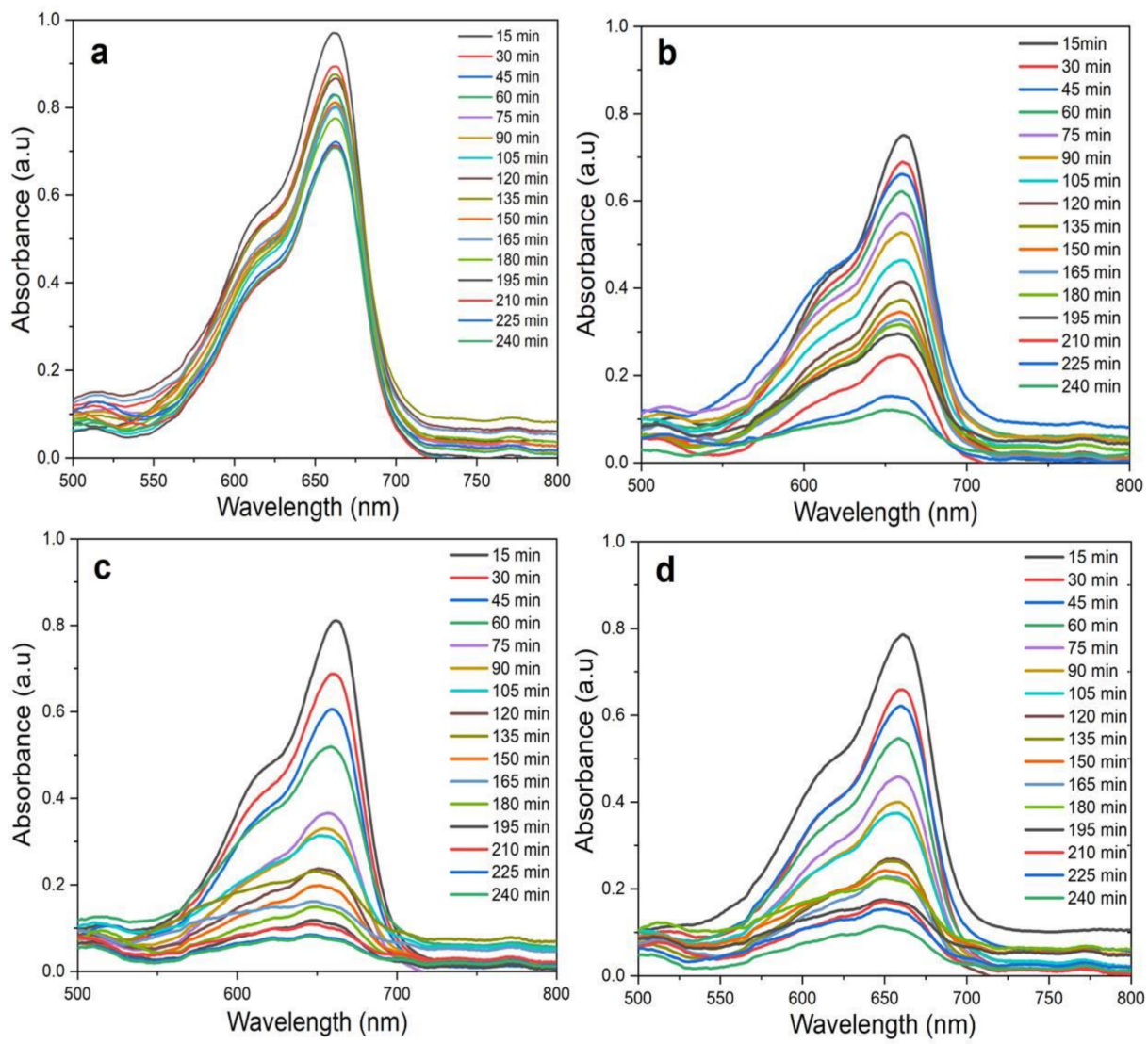

Figure 13. UV-Vis spectra of $\mathrm{MB}$ photodegradation under radiation under optimized conditions (20 mg catalyst, $5 \mathrm{ppm} \mathrm{MB}$, and $\mathrm{pH} \mathrm{6,} \mathrm{at} \mathrm{RT)} \mathrm{during} \mathrm{a} \mathrm{time} \mathrm{course} \mathrm{period} \mathrm{of} 240 \mathrm{~min}$. (a) Control (without ZnO NPs); (b) ZnO NPs/TPL; (c) ZnO NPs/TPS; (d) ZnO NPs/TPF.

The half-life of the MB dye degradation by biosynthesized NPs was taken at the crossover point of curves $\mathrm{C} / \mathrm{Co}$ and $[1-\mathrm{C} / \mathrm{Co}] \times 100 \%$ (Figure 14). Degradation efficiency for ZnO NPs/TPL (Figure 14a), ZnO NPs/TPS (Figure 14b), ZnO NPs/TPF (Figure 14c) was measured for the duration of $240 \mathrm{~min}$, and the plots were generated for calculating the half-life and degradation efficiencies. 


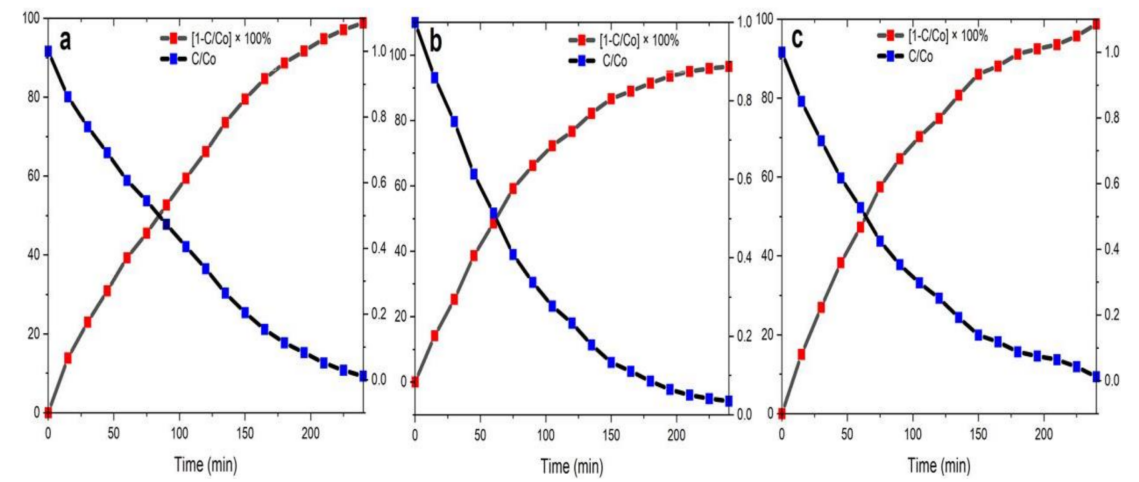

Figure 14. Half-life of the photocatalytic degradation rate of MB by NPs as the catalyst. (a) ZnO NPs/TPL;(b) ZnO NPs/TPS;(c) ZnO NPs/TPF.

The following equation was used to calculate the degradation efficiency of the MB:

Degradation efficiency $(\%)=\frac{C_{0}-C}{C_{0}} \times 100$ where Co is the initial concentration of $\mathrm{MB}$ dye solution ( $\mathrm{mg} \mathrm{L}^{-1}$ ) and $\mathrm{C}$ is the concentration of the $\mathrm{MB}$ dye solution $\left(\mathrm{mg} \mathrm{L}^{-1}\right)$ after a certain time of irradiation.

Importantly, when the MB dye solution was exposed to sunlight for $240 \mathrm{~min}$ in the presence of the biosynthesized ZnO NPs, the degradation efficiency of the MB dye reached up to $99 \%$. Indeed, the highest degradation of $98.86 \%$ was obtained for ZnO NPs/TPL, with a half-lifetime of $84.7 \mathrm{~min}$, negligibly followed by ZnO NPs/TPS and ZnO NPs/TPF of $98.15 \%$ and $95.80 \%$, with half-lifetimes of $52.9 \mathrm{~min}$ and $65.1 \mathrm{~min}$, respectively.

Altogether, these data exhibit strong photostability of ZnO NPs synthesized from different parts of the same plant. It was found that small crystallite size enhances the probability of charge recombination outside the barrier region and photodegradation. As per the XRD and TEM analysis, the ZnO NPs/TPS showed the highest surface area, followed by ZnO NPs/TPL and ZnO NPs/TPF. Nevertheless, PL studies revealed that ZnO NPs/TPL exhibit maximum PL effect, which reduced the electron-hole recombination on the surface of the catalyst, subsequently leading to the highest photodegradation effect.

\section{Conclusions}

To the best of our knowledge, this is the first study using leaves, stem, and inflorescence of the Sri Lankan native medicinal plant T. purpurea to phytofabricate multifunctional $\mathrm{ZnO}$ NPs. The freshly made phytogenic ZnO NPs exhibited a hexagonal wurtzite structure with an absorption maximum in the range of 350-380 $\mathrm{nm}$. FTIR analysis showed the presence of surface-adhered phytoconstituents, like flavonols, phenols, alcohol, tannins, and amines, which actively contributed to the stabilization of the ZnO NPs. SEM micrographs produced flower- and spherical-like arrangements of nanocrystals. TEM images confirmed the formation of spherical NPs with an average crystallite size of 25-35 nm. Importantly, FRET activity of the phytogenic ZnO NPs between the two fluorescent dyes, Flu and RhB, was evaluated for the first time. It was found that energy transfer efficiency between the dye molecules increased in the presence of ZnO NPs, and the maximum efficiency of $77.45 \%$ was found for the $\mathrm{ZnO}$ NPs synthesized via inflorescences extract. PL intensities of phytosynthesized $\mathrm{ZnO}$ NPs were higher and asymmetric compared with the chemically synthesized $\mathrm{ZnO}$ NPs, which is a valuable finding since luminescence represents a key feature in the development of optoelectric devices. Besides, synthesized ZnO NPs elicited a fascinating photocatalytic degradation of $\mathrm{MB}$, which reduced the electron-hole recombination on the surface of the NPs. The highest photocatalytic performance of $99 \%$ was exhibited by ZnO NPs synthesized via leaves extract. Overall, the obtained results showed that greenly synthesized ZnO NPs should be a preferred option compared to chemically synthesized ZnO NPs in many areas encompassing biomedical, environmental, and industrial applications. 
Supplementary Materials: The following are available online at https:/ / www.mdpi.com/2071-105 0/13/4/2004/s1, Figure S1: SEM Images of obtained for ZnO NPs/TPL at magnitudes of 15,000 and 50,000 at $10000 \mathrm{kV}$, Figure S2: SEM Images of obtained for ZnO NPs/TPS at magnitudes of 15,000 and 50,000 at 10,000 kV, Figure S3: SEM Images of obtained for ZnO NPs/TPF at magnitudes of 15,000 and 50,000 at 10,000 kV, Table S1: Crystal size calculated for ZnO NPs/TPS using Debye-Scherrer's formula, Table S2: Crystal size calculated for ZnO NPs/TPF using Debye-Scherrer's formula.

Author Contributions: Conceptualization; G.T.; Data curation; G.T., U.W., F.M.; Formal analysis G.T., U.W., F.M.; Funding acquisition G.T.; Investigation G.T., U.W.; Methodology G.T., U.W., H.I., F.M.; Project administration G.T.; Resources G.T.; Software G.T., U.W., H.I.; Supervision G.T.; Validation G.T., F.M.; Visualization G.T.; Roles/Writing—original draft G.T., U.W.; Writing—review \& editing G.T., U.W., F.M. All authors have read and agreed to the published version of the manuscript.

Funding: This research was funded by Institute of Chemistry Ceylon, College of Chemical Sciences.

Institutional Review Board Statement: Not Applicable.

Informed Consent Statement: Not applicable.

Data Availability Statement: The data presented on this study are available on request from the corresponding author.

Acknowledgments: College of Chemical Sciences, Institute of Chemistry Ceylon, Sri Lanka, is acknowledged for the continued support.

Conflicts of Interest: The authors declare that they have no conflict of interest.

Submission Declaration and Verification: This study was not pre-registered.

\begin{tabular}{ll}
\multicolumn{2}{l}{ Abbreviations } \\
DI $\mathrm{H}_{2} \mathrm{O}$ & Deionized water \\
$\mathrm{DLS}$ & Dynamic light scattering \\
$\mathrm{Flu}$ & Fluorescein \\
FRET & Fluorescence resonance energy transfer \\
FTIR & Fourier transform infrared \\
$\mathrm{MB}$ & Methylene blue \\
$\mathrm{MeOH}$ & Methanol \\
$\mathrm{MONPs}$ & Metal oxide nanoparticles \\
$\mathrm{NPs}$ & Nanoparticles \\
• OH & Hydroxyl radicals \\
PDI & Polydispersity index \\
$\mathrm{PL}$ & Photoluminescence \\
PS & Particle size \\
RhB & Rhodamine B \\
RT & Room temperature \\
SEM & Scanning electron microscopy \\
SPR & Surface plasmon resonance \\
TEM & Transmission electron microscopy \\
T. purpurea & Tephrosia purpurea \\
UV-Vis & Ultraviolet-Visible \\
XRD & X-ray diffraction \\
ZnO & Zinc oxide
\end{tabular}

\section{References}

1. Gnanasekaran, L.; Hemamalini, R.; Saravanan, R.; Ravichandran, K.; Gracia, F.; Agarwal, S.; Gupta, V.K. Synthesis and characterization of metal oxides $\left(\mathrm{CeO}_{2}, \mathrm{CuO}, \mathrm{NiO}, \mathrm{Mn}_{3} \mathrm{O}_{4}, \mathrm{SnO}_{2}\right.$ and $\left.\mathrm{ZnO}\right)$ nanoparticles as photo catalysts for degradation of textile dyes. J. Photochem. Photobiol. B Biol. 2017, 173, 43-49. [CrossRef]

2. Suresh, D.; Shobharani, R.; Nethravathi, P.; Kumar, M.P.; Nagabhushana, H.; Sharma, S. Artocarpus gomezianus aided green synthesis of $\mathrm{ZnO}$ nanoparticles: Luminescence, photocatalytic and antioxidant properties. Spectrochim. Acta Part A Mol. Biomol. Spectrosc. 2015, 141, 128-134. [CrossRef] 
3. Mishra, S.; Srivastava, R.; Prakash, S.; Yadav, R.S.; Panday, A. Photoluminescence and photoconductive characteristics of hydrothermally synthesized ZnO nanoparticles. Opto-Electron. Rev. 2010, 18, 467-473. [CrossRef]

4. Hahm, J.-I. Zinc Oxide Nanomaterials for Biomedical Fluorescence Detection. J. Nanosci. Nanotechnol. 2014, 14, 475-486. [CrossRef] [PubMed]

5. Basavalingiah, K.R.; Harishkumar, S.; Udayabhanu; Nagaraju, G.; Rangappa, D. Chikkahanumantharayappa Highly porous, honeycomb like $\mathrm{Ag}-\mathrm{ZnO}$ nanomaterials for enhanced photocatalytic and photoluminescence studies: Green synthesis using Azadirachta indica gum. SN Appl. Sci. 2019, 1. [CrossRef]

6. Koshy, J.; Samuel, M.S.; Chandran, A.; George, K.C.; Predeep, P.; Thakur, M.; Varma, M.K.R. Optical Properties of CuO Nanoparticles. AIP Conf. Proc. 2011, 1391, 576-578. [CrossRef]

7. Jeevanandam, J.; Chan, Y.S.; Danquah, M.K. Biosynthesis of Metal and Metal Oxide Nanoparticles. ChemBioEng Rev. 2016, 3, 55-67. [CrossRef]

8. Kuruppu, K.A.S.S.; Perera, K.M.K.G.; Chamara, A.M.R.; Thiripuranathar, G. Flower shaped ZnO-NPs; phytofabrication, photocatalytic, fluorescence quenching, and photoluminescence activities. Nano Express 2020, 1, 020020. [CrossRef]

9. Saleh, S.M. Metal Oxide Nanomaterials as Photo-Catalyst for Dye Degradation. Res. Dev. Mater. Sci. 2019, 9, 1-8. [CrossRef]

10. Suresh, D.; Nethravathi, P.; Udayabhanu; Rajanaika, H.; Nagabhushana, H.; Sharma, S. Green synthesis of multifunctional zinc oxide $(\mathrm{ZnO})$ nanoparticles using Cassia fistula plant extract and their photodegradative, antioxidant and antibacterial activities. Mater. Sci. Semicond. Process. 2015, 31, 446-454. [CrossRef]

11. Babu, K.S.; Reddy, A.R.; Sujatha, C.; Reddy, K.V. Optimization of UV emission intensity of ZnO nanoparticles by changing the excitation wavelength. Mater. Lett. 2013, 99, 97-100. [CrossRef]

12. Giri, P.K.; Bhattacharyya, S.; Singh, D.K.; Kesavamoorthy, R.; Panigrahi, B.K.; Nair, K.G.M. Correlation between microstructure and optical properties of $\mathrm{ZnO}$ nanoparticles synthesized by ball milling. J. Appl. Phys. 2007, 102, 093515. [CrossRef]

13. Talakonda, P.R. Excitation-Intensity (EI) Effect on Photoluminescence of ZnO Materials with Various Morphologies. Lumin. Outlook Phenom. Appl. 2016, 16. [CrossRef]

14. Saha, J.; Roy, A.D.; Dey, D.; Bhattacharjee, D.; Paul, P.K.; Das, R.; Hussain, S. Effect of Zinc oxide nanoparticle on Fluorescence Resonance Energy transfer between Fluorescein and Rhodamine 6G. Spectrochim. Acta Part A Mol. Biomol. Spectrosc. 2017, 175, 110-116. [CrossRef]

15. Sabir, S.; Arshad, M.; Chaudhari, S.K. Zinc Oxide Nanoparticles for Revolutionizing Agriculture: Synthesis and Applications. Sci. World J. 2014, 2014, 1-8. [CrossRef]

16. Kumar, A. Performance analysis of Zinc oxide based alcohol sensors. Int. J. Appl. Sci. Eng. Res. 2015, 4, 427-436.

17. Solati, E.; Dorranian, D. Effect of temperature on the characteristics of ZnO nanoparticles produced by laser ablation in water. Bull. Mater. Sci. 2016, 39, 1677-1684. [CrossRef]

18. Kumar, H.; Rani, R. Structural and Optical Characterization of ZnO Nanoparticles Synthesized by Microemulsion Route. Int. Lett. Chem. Phys. Astron. 2013, 19, 26-36. [CrossRef]

19. Sharma, A.; Singh, B.; Dhar, S.; Gondorf, A.; Spasova, M. Effect of surface groups on the luminescence property of ZnO nanoparticles synthesized by sol-gel route. Surf. Sci. 2012, 606, L13-L17. [CrossRef]

20. Alamdari, S.; Ghamsari, M.S.; Lee, C.; Han, W.; Park, H.-H.; Tafreshi, M.J.; Afarideh, H.; Ara, M.H.M. Preparation and Characterization of Zinc Oxide Nanoparticles Using Leaf Extract of Sambucus ebulus. Appl. Sci. 2020, 10, 3620. [CrossRef]

21. Rashad, M.; Shaalan, N.M.; Abd-Elnaiem, A.M. Degradation enhancement of methylene blue on ZnO nanocombs synthesized by thermal evaporation technique. Desalin. Water Treat. 2016, 57, 26267-26273. [CrossRef]

22. Jin, S.-E.; Jin, H.-E. Synthesis, Characterization, and Three-Dimensional Structure Generation of Zinc Oxide-Based Nanomedicine for Biomedical Applications. Pharmaceutics 2019, 11, 575. [CrossRef]

23. Jamdagni, P.; Khatri, P.; Rana, J. Green synthesis of zinc oxide nanoparticles using flower extract of Nyctanthes arbor-tristis and their antifungal activity. J. King Saud Univ. Sci. 2018, 30, 168-175. [CrossRef]

24. Iravani, S. Green synthesis of metal nanoparticles using plants. Green Chem. 2011, 13, 2638-2650. [CrossRef]

25. Hussain, I.; Singh, N.B.; Singh, A.; Singh, H.; Singh, S.C. Green synthesis of nanoparticles and its potential application. Biotechnol. Lett. 2016, 38, 545-560. [CrossRef]

26. Shah, M.; Fawcett, D.; Sharma, S.; Tripathy, S.K.; Poinern, G.E.J. Green Synthesis of Metallic Nanoparticles via Biological Entities. Materials 2015, 8, 7278-7308. [CrossRef] [PubMed]

27. Akhtar, M.S.; Panwar, J.; Yun, Y.-S. Biogenic Synthesis of Metallic Nanoparticles by Plant Extracts. ACS Sustain. Chem. Eng. 2013, 1, 591-602. [CrossRef]

28. Kalra, S.; Khanna, D. Tephrosia Purpurea-A Magical Herb with Blessings in Human Biological System. Int. J. Recent Adv. Pharm. Res. 2013, 3, 12-22.

29. Jisha, E.; Balamurugan, G. Biogenic synthesis of Gold Nanoparticles using leaf extract of Tephrosia purpurea and study of their antibacterial effect. Int. J. Pharm. Tech. 2012, 4, 1323-1331.

30. Lodhi, S.; Jain, A.; Jain, A.P.; Pawar, R.S.; Singhai, A.K. Effects of flavonoids from Martynia annua and Tephrosia purpurea on cutaneous wound healing. Avicenna J. Phytomed. 2016, 6, 578-591.

31. Patel, A.; Patel, A.; Patel, N.M. Estimation of Flavonoid, Polyphenolic Content and In-Vitro Antioxidant Capacity of leaves of Tephrosia purpurea. Int. J. Pharma. Sci. Res. 2010, 1, 66-77. 
32. Nile, S.H.; Khobragade, C.N. Phytochemical analysis, antioxidant and xanthine oxidase inhibitory activity of Tephrosia purpurea Linn. Root Extract. Indian J. Nat. Prod. Resour. 2011, 2, 52-58.

33. Padmapriya, R.; Ashwini, S.; Raveendran, R. In vitro antioxidant and cytotoxic potential of different parts of Tephrosia purpurea. Res. Pharm. Sci. 2017, 12, 31-37. [CrossRef]

34. Dey, D.; Bhattacharjee, D.; Chakraborty, S.; Hussain, S. Development of hard water sensor using fluorescence resonance energy transfer. Sensors Actuators B Chem. 2013, 184, 268-273. [CrossRef]

35. Tovmachenko, O.G.; Graf, C.; Heuvel, D.J.V.D.; Van Blaaderen, A.; Gerritsen, H.C. Fluorescence Enhancement by MetalCore/Silica-Shell Nanoparticles. Adv. Mater. 2006, 18, 91-95. [CrossRef]

36. Yue, Q.; Cheng, J.; Li, G.; Zhang, K.; Zhai, Y.; Wang, L.; Liu, J. Fluorescence Property of ZnO Nanoparticles and the Interaction with Bromothymol Blue. J. Fluoresc. 2010, 21, 1131-1135. [CrossRef] [PubMed]

37. Saha, J.; Roy, A.D.; Dey, D.; Bhattacharjee, D.; Hussain, S. Role of quantum dot in designing FRET based sensors. Mater. Today Proc. 2018, 5, 2306-2313. [CrossRef]

38. Kalele, S.; Deshpande, A.C.; Singh, S.B.; Kulkarni, S.K. Tuning luminescence intensity of RHO6G dye using silver nanoparticles. Bull. Mater. Sci. 2008, 31, 541-544. [CrossRef]

39. Aminuzzaman, M.; Ying, L.P.; Goh, W.-S.; Watanabe, A. Green synthesis of zinc oxide nanoparticles using aqueous extract of Garcinia mangostana fruit pericarp and their photocatalytic activity. Bull. Mater. Sci. 2018, 41, 50. [CrossRef]

40. Nethravathi, P.; Shruthi, G.; Suresh, D.; Udayabhanu; Nagabhushana, H.; Sharma, S. Garcinia xanthochymus mediated green synthesis of $\mathrm{ZnO}$ nanoparticles: Photoluminescence, photocatalytic and antioxidant activity studies. Ceram. Int. 2015, 41, 8680-8687. [CrossRef]

41. Osman, D.; Mustafa, M. Synthesis and Characterization of Zinc Oxide Nanoparticles using Zinc Acetate Dihydrate and Sodium Hydroxide. J. Nanosci. Nanoeng. 2015, 1, 248-251.

42. Gnanasangeetha, D.; Saralathambavani, D. One Pot Synthesis of Zinc Oxide Nanoparticles via Chemical and Green Method. Res. J. Mater. Sci. 2013, 1, 1-8.

43. Jung, D.-R.; Kim, J.; Nahm, C.; Choi, H.; Nam, S.; Park, B. Review paper: Semiconductor nanoparticles with surface passivation and surface plasmon. Electron. Mater. Lett. 2011, 7, 185-194. [CrossRef]

44. Choyke, W.J. Optical and Electronic Properties of SiC. Phys. Chem. Carbides Nitrides Borides 1990, 1990, 563-587. [CrossRef]

45. Kuppusamy, P.; Yusoff, M.M.; Maniam, G.P.; Govindan, N. Biosynthesis of metallic nanoparticles using plant derivatives and their new avenues in pharmacological applications-An updated report. Saudi Pharm. J. 2016, 24, 473-484. [CrossRef] [PubMed]

46. Bhuyan, T.; Mishra, K.; Khanuja, M.; Prasad, R.; Varma, A. Biosynthesis of zinc oxide nanoparticles from Azadirachta indica for antibacterial and photocatalytic applications. Mater. Sci. Semicond. Process. 2015, 32, 55-61. [CrossRef]

47. Vaseem, M.; Umar, A.; Hahn, Y. ZnO Nanoparticles: Growth, Properties, and Applications. Metal Oxide Nanostruct. Their Appl. 2010, 5, 1-36.

48. Attar, A.; Yapaoz, M.A. Biomimetic synthesis, characterization and antibacterial efficacy of $\mathrm{ZnO}$ and Au nanoparticles using echinacea flower extract precursor. Mater. Res. Express 2018, 5, 055403. [CrossRef]

49. El Shafey, A.M. Green synthesis of metal and metal oxide nanoparticles from plant leaf extracts and their applications: A review. Green Process. Synth. 2020, 9, 304-339. [CrossRef]

50. Gnanasangeetha, D.; Thambavani, D. Biological and Physical Sciences Biogenic Production of Zinc Oxide Nanoparticles Using Acalypha Indica. J. Cjemical. Biol. Phys. Sci. 2014, 4, 238-246.

51. Handore, K.; Bhavsar, S.; Horne, A.; Chhattise, P.; Mohite, K.; Ambekar, J.; Pande, N.; Chabukswar, V.V. Novel Green Route of Synthesis of ZnO Nanoparticles by Using Natural Biodegradable Polymer and Its Application as a Catalyst for Oxidation of Aldehydes. J. Macromol. Sci. Part A 2014, 51, 941-947. [CrossRef]

52. Sakr, M.E.M.; Kana, M.T.H.A.; Fattah, G.A. Fluorescence enhancement monitoring of pyrromethene laser dyes by metallic Ag nanoparticles. Luminescence 2014, 29, 938-944. [CrossRef] [PubMed]

53. Tishchenko, K.; Muratova, M.; Volkov, D.; Filichkina, V.; Nedosekin, D.; Zharov, V.; Proskurnin, M. Multi-wavelength thermal-lens spectrometry for high-accuracy measurements of absorptivities and quantum yields of photodegradation of a hemoprotein-lipid complex. Arab. J. Chem. 2017, 10, 781-791. [CrossRef]

54. Klonis, N.; Clayton, A.H.A.; Voss, E.W.; Sawyer, W.H. Spectral Properties of Fluorescein in Solvent-Water Mixtures: Applications as a Probe of Hydrogen Bonding Environments in Biological Systems. Photochem. Photobiol. 1998, 67, 500. [CrossRef]

55. Li, H.; Zhang, C.; Li, X.-F.; Xiang, J.; Tie, S.-L.; Lan, S. Enhanced upconversion luminescence from ZnO/Zn hybrid nanostructures induced on a Zn foil by femtosecond laser ablation. Opt. Express 2015, 23, 30118-30126. [CrossRef]

56. Dey, D.; Saha, J.; Roy, A.D.; Bhattacharjee, D.; Hussain, S.A. Development of an ion-sensor using fluorescence resonance energy transfer. Sensors Actuators B Chem. 2014, 195, 382-388. [CrossRef]

57. Singh, R.P.; Baghel, R.S.; Reddy, C.R.K.; Jha, B. Effect of quorum sensing signals produced by seaweed-associated bacteria on carpospore liberation from Gracilaria dura. Front. Plant Sci. 2015, 6, 117. [CrossRef]

58. Chitradevi, T.; Lenus, A.J.; Jaya, N.V. Structure, morphology and luminescence properties of sol-gel method synthesized pure and Ag-doped ZnO nanoparticles. Mater. Res. Express 2019, 7, 015011. [CrossRef]

59. Wang, Z.; Huang, B.; Liu, X.; Qin, X.; Zhang, X.; Wei, J.; Wang, P.; Yao, S.; Zhang, Q.; Jing, X. Photoluminescence studies from $\mathrm{ZnO}$ nanorod arrays synthesized by hydrothermal method with polyvinyl alcohol as surfactant. Mater. Lett. 2008, 62, 2637-2639. [CrossRef] 
60. Siddiqi, K.S.; Rahman, A.U.; Tajuddin; Husen, A. Properties of Zinc Oxide Nanoparticles and Their Activity Against Microbes. Nanoscale Res. Lett. 2018, 13, 1-13. [CrossRef] [PubMed]

61. Taha, S.A.; Abd-Elnaiem, A.M.; Mohamed, M.; Mostafa, S.; Mostafa, M. Structural study and photocatalytic performance of ZnO thin films prepared by electrochemical deposition. Desalin. Water Treat. 2017, 100, 160-167. [CrossRef]

62. Fatehah, M.O.; Aziz, H.A.; Stoll, S. Stability of ZnO Nanoparticles in Solution. Influence of pH, Dissolution, Aggregation and Disaggregation Effects. J. Colloid Sci. Biotechnol. 2014, 3, 75-84. [CrossRef] 